\title{
El trabajo \\ y la vida cotidiana. \\ Un enfoque desde los espacios de vida*.
}

\author{
Alicia Lindón Villoria \\ El Colegio Mexiquense \\ Ex-Hacienda Santa Cruz de los Patos \\ Apartado Postal 48-D \\ Toluca 50120, Estado de México
}

Tel (72) 180056

Fax (72) 180358

\section{Resumen}

- En este artículo se plantea un camino metodológico para tratar el estudio de la vida cotidiana y su relación con el trabajo, desde la perspectiva de los espacios de vida de los individuos. En este sentido, la propuesta es partir de la interacción entre la vida cotidiana, subdividida en cuatro ámbitos (doméstico, laboral, vecinal y tiempo libre), y la relación trabajo/residencia (o la espacialidad del trabajo)." La interacción entre estas dos esferas la denomino "trama de la vida cotidiana". Al concebir a esta última como la articulación de vínculos sociales

* Estas reflexiones se han desarrollado en el contexto de nuestra tesis doctoral "El trabajo y la vida cotidiana. Los modos de vida urbanos en el valle de Chalco", Centro de Estudios Sociológicos, El Colegio de México, 1996. Esta investigación ha contado con el apoyo del Seminario de Estudios de la Cultura de la Dirección General de Culturas Populares, CONACURTA. Asimismo, se ha recibido el apoyo de una beca C.B. Smith del Institute of Latin American Studies de la Universidad de Texas, en Austin. Los antecedentes de este texto fueron presentados en Encontro Internacional: Lugar, formaçâo sócio espacial, mundo, $(\mathrm{O}$ lugar e a produçâo do cotidiano), San Pablo, septiembre de 1994.

"* Relación trabajo/residencia: relación T/R. 
(definidos en función de las actividades cotidianas) y un fondo espacio-temporal, es posible llegar a diferenciar tramas dispersas espacialmente y fraccionadas en términos temporales, y tramas cotidianas concentradas en ciertos espacios de vida y continuas en el tiempo cotidiano.

\section{Introducción}

En este trabajo se presenta una propuesta metodológica para estudiar la relación entre el trabajo y la vida cotidiana desde un enfoque espacio-temporal. De esta manera, el artículo se integra de tres apartados. El primero se dedica a la revisión de los contenidos que frecuentemente adopta el enfoque espacial en el pensamiento social actual, distinguiendo dos posiciones opuestas. En una de ellas el espacio interesa en un nivel macrosocial y en su dimensión material; en la otra, el espacio se incorpora como vivencia desde un nivel microsocial. En este segundo contexto se ubica la propuesta metodológica desarrollada en los dos apartados siguientes.

En el segundo apartado se analiza la importancia de regresar analíticamente a la categoría trabajo como una forma de comprende la vida cotidiana de las personas. Esto implica ubicar al trabajo desde la perspectiva de los individuos. La especificidad de esta propuesta radica en entender al trabajo desde su espacialidad antes que desde otras dimensiones más conocidas, como por ejemplo las formas de inserción laboral.

Por último, en el tercer apartado se presenta la propuesta metodológica a partir del tratamiento simultáneo de la espacialidad del trabajo y los ámbitos en los que se subdivide la vida cotidiana. Esta doble entrada representa un camino para comprender la trama de la vida cotidiana, entendida como un conjunto de relaciones sociales que se dispersan en distintos espacios de vida y se fragmentan en diferentes tiempos.

\section{El espacio en el pensamiento social de fin de siglo}

Los intelectuales de las ciencias sociales actualmente parecen orientarse hacia dos ámbitos principales del conocimiento en los que se está canalizando la mayor parte de las reflexiones que ofrecen esquemas interpretativos de la realidad social de este fin de siglo. Muy esquemáticamente podríamos decir que uno de estos ámbitos del pensamiento actual es el dominado por la idea de "mundialización", en donde se da una relativa preeminencia a la dimensión económica. Sin embargo, la regencia de lo económico no impide que detrás de ello aparezcan alineadas otras dimensiones como la política, la sociológica y, a veces, la territorial. Respecto a esta última dimensión, podemos recordar el interés de los geógrafos y espacialistas en general por el tema de las ciudades mundiales, los distritos industriales, los flujos informáticos, etcétera.

Así, se hablade mundialización, globalización, conformación de bloques económicos, grandes áreas de libre mercado, reestructuración de los procesos productivos y de trabajo y de una verdadera revolución tecnológica. En términos territoriales no debe omitirse el interés por la reestructuración de las viejas regiones industriales y la conformación de distritos de la misma índole, así como también de otros fenómenos asociados a éstos; no olvidemos el interés por la denominada "informalidad urbana".

Una cuestión significativa es que para este ámbito del pensamiento, el espacio (particularmente el espacio-mundial) ha ido cobrando interés creciente; de una manera o de otra, está presente en los diversos discursos, aunque no siempre de manera consistente. Así, a pesar de que frecuentemente no ha pasado de ser un simple espacio-soporteen el que ocurren fenómenos económicos, o bien, el recorte espacial de un proceso socioeconómico, su sola consideración (por más limitada que sea) puede ser un paso adelante si lo evaluamos en el contexto de un pensamiento socioeconómico fuertemente aespacializado.

Se puede demarcar un segundo ámbito del pensamiento de este fin de siglo', conformado en torno a la subjetividad, a lo microsocial, lo local, la vida cotidiana, el mundo de lo doméstico, los modos de vida en nuestras metrópolis y megalópolis.

En este caso, se defiende (porque estas dimensiones aún no gozan de demasiado estatus científico, como ocurre con lo económico o lo político) la importancia del retorno a la subjetividad, al individuo y la persona, a lo vivencial, al presente, a la afectividad y la emotividad, a lo lúdico y onírico, como esferas esenciales para comprender al hombre actual y a la vida social en su conjunto. En

\footnotetext{
'Me refiero a buena parte de lo que se conoce como el pensamiento de la
} posmodernidad". 
esta perspectiva se ha tornado esencial incorporar lo "no racional", lo que no responde a fines claros, lo que se aleja de la racionalidad instrumental, que supuestamente regía y explicaba casi todas las acciones del hombre de la modernidad (Touraine, 1994)2. Esta es una forma de reconocimiento científico de un individuo más complejo que aquel cuyas acciones se podían explicar enteramente por la racionalidad instrumental.

Recordemos que, por ejemplo, Michel Maffesoli (1991,1992 y 1993) ha planteado que lo "social" está siendo sustituido por una "socialidad de base ${ }^{\mathrm{n}}$, que los "individuos" caracterizados por funciones sociales dejan el lugar a las "personas", definidas por desarrollar múltiples roles cambiantes antes que una función precisa y establecida. Los "grupos contractuales" (porejemplo los sindicatos) pierden importancia frente a las "tribus afectivas". Lo "político", que siempre se ha asociado al futuro como el espacio de las metas y los proyectos actuales, pierde terreno frente al retorno a la "comunidad", a una suerte de tribalismo, a un reencantamiento del mundo, que se vive en un aquí espacializado y un ahora (el presente, que no piensa en la historia). Desde esta perspectiva, lo imaginario ha ido definiendo un estatus científico; por ejemplo, se han constituido centros de investigación sobre lo imaginario ${ }^{3}$.

En este segundo ámbito del pensamiento actual, el espacio, $\mathrm{y}$ en particular los microespacios, se han constituido en un componente central del análisis, a pesar de no tratarse de análisis geográficos o planteados desde una perspectiva expresamente espacial. Toda esta reflexión, al encontrar raíces fenomenológicas, parte de un individuo situado en un aquí y un ahora; por ello el desarrollo de este pensamiento ha incluido el análisis de esas dos coordenadas (espacio y tiempo), con la particularidad de que son consideradas desde las vivencias espacio-temporales de los propios sujetos. Por ejemplo, Berger y Luckmann, aunque dan prioridad al tiempo, destacan que "el mundo de la vida cotidiana se estructura tanto en el espacio como en el tiempo" (Berger y Luckmann, 1968:44).

${ }^{2}$ De acuerdo con la propuestade Alain Touraine deberíamos ubicar el predominio de esta racionalidad instrumental en el contexto de la "modernidad limitada", que se transforma actualmente en una "modernidad plena", en lugar de la posmodernidad.

${ }^{3}$ Recordemos el Centro de Investigaciones sobre lo Imaginario, dirigido por Gilbert Durand.

Estas tendencias sobrepasan ampliamente el campo disciplinario de la geografía, que siempre tuvo un monopolio relativo sobre lo espacial; más aún, el actual interés por el espacio asociado a la subjetividad, "el espacio vivido", no se ha iniciado en esta disciplina, a pesar de los intentos más o menos pioneros de la geografía de las percepciones en los años setenta, que dieron origen a la geografía de las representaciones en la década de los ochenta. Así, hoy el espacio asociado a lo vivencial y a la subjetividad es sujeto de estudio también de la sociología, la antropología, la etnografía... Este proceso no deja de tener repercusiones en el campo de la geografía, en donde lo que fueron intentos aislados y no legitimados institucionalmente como ocurría con los trabajos de Armand Frémont en los años setenta (Frémont, 1976), hoy comienzan a retroalimentarse de los aportes de otras disciplinas sociales como la sociología del conocimiento (Bailly, 1992:371-384; Bailly y Debarbieux, 1991:153-161; García Ballesteros, 1986:13-27).

La descalificación de la subjetividad que dos décadas atrás se producía entre los espacialistas también se daba en otros ámbitos del pensamiento social. Algo semejante ocurría con trabajos como los de Gilbert Durand (1981) en la antropología, o los de Pierre Sansot (1971) en la sociología.

De acuerdo con el pensamiento de nuestro fin de siglo, no podemos dejar de considerar a otros actores intelectuales; aquellos que siguen aferrados a las determinaciones cuasidirectas de lo estructural. Para éstos, toda esta corriente subjetivista es juzgada, no sin un cierto aire deslegitimador, como la "huida a la subjetividad", como un nuevo solipsismo de fin de siglo. Locierto es que sin negar la importancia de lo estructural, destacados autores procedentes del análisis de lo estructural y de lo macrosocial, como Ralf Dahrendorf (1979) o Adam Przeworski (1982:58-99) han mostrado que ante unas mismas condiciones estructurales los individuos encuentran diferentes formas de organizar la vida (life chances, en palabras de Dahrendorf) 4 , y diferentes formas de percibir y organizar su espacio.

Aun cuando estas posiciones no dejan de ser aproximaciones estructural-funcionalistas, que conciben las acciones humanas como reacciones ante el sistema (Michel, 1974:19), es importante el reconocimiento, por parte de autores muy lejanos al pensamiento

4 Cabe señalar que tanto Adam Przeworski como Ralf Dahrendorf reviven (directa o indirectamente) la categoría de estructura de oportunidades que Wright Mills usaba en los años cincuenta (Wright Mills, 1961:28). 
subjetivista, de la multiplicidad de hechos posibles ante un mismo fenómeno desencadenante.

En suma, el pensamiento social de este fin de siglo, tanto el que se amarra en la mundialización o bien el que lo hace en la subjetividad, incorpora el espacio, se espacializa. Se redescubre el espacio; aquel que los individuos en su vida cotidiana siempre incorporaron, porque el hombre es un ser espacializado (Ortega y Gasset, 1983:339-343) ${ }^{5}$, pero que los intelectuales de las ciencias sociales han tenido tantas dificultades para incluir en su discurso y mucho más aún, en su análisis,

La perspectiva de la mundialización-globalización (descontando los casos en los que el espacio es un simple recurso para delimitar un fenómeno) cuando considera al espacio lo hace en términos de "organización espacial". En cambio, la segunda de estas perspectivas, la subjetivista, considera al espacio desde la visión de "las prácticas espacializadas de los individuos y las representaciones e imágenes del espacio" que las personas manejan y con las que se orientan cotidianamente en su quehacer.

Es consecuencia de lo anterior que en el primer caso sean frecuentes los análisis que parten de la dimensión macrosocial; directa o indirectamente se habla de la organización del espacio. Mietras que en el segundo caso la tendencia es a desarrollar análisis de tipo microsocial, de corte predominantemente cualitativo, que parten de un Ego espacializado (un individuo situado en un aquí y un ahora). Se marca, así, un nuevo retorno a la fenomenología. consideraciones no niegan los distintos intentos por conocer los vínculos entre los análisis de tipo macro y microsocial, de lo cual puede ser un ejemplo la obra de Anthony Giddens, que significativamente busca puentes entre la sociología y la geografía (Giddens, 1995:39-76 y 143-175).

En este bosquejo muy esquemático del pensamiento social, este artículo se ubica en la segunda perspectiva aquí planteada, la subjetivista y espacialista. En esta ocasión sólo se presentan algunos elementos de la estrategia metodológica seguida en la investigación que da origen a este artículo, y no resultados empíricos de la

${ }^{5}$ José Ortega y Gasset decía que el espacio representa para el hombre una eterna condena. Su existencia siempre está espacializada, aunque esté en constante movimiento y sea capaz de adaptarse a cualquier espacio. investigación ${ }^{6}$. Sin embargo, se debe señalar que este camino metodológico se ha ido construyendo en relación con un particular fragmento de la realidad metropolitana de la ciudad de México ${ }^{7}$.

\section{El trabajo como categoría mediadora entre lo histórico y la vida} cotidiana

En este artículo no se pretende trabajar sobre los vínculos entre la visión microsocial, de corte subjetivista, y la macrosocial, asociada a la mundialización-globalización, aunque interesa tener presente lo macro como un contexto desencadenante de ciertos fenómenos que resultan procesados de muy distintas formas en la vida cotidiana de las personas, En otras palabras, se entienden los macroprocesos como contextos que residen de distintas maneras en las microsituaciones. Desde esta visión, resultaparticularmente relevante considerar "el trabajo" (no mè refiero al empleo ni a la inserción laboral), ya que es una categoría que puede facilitar el establecimiento de ciertos vínculos entre la escala macrosocial y la de la cotidianidad.

En cierta forma puede servir de sustento la ya clásica diferenciación entre work y labour, particularmente en los términos planteados por Agnes Heller. Recordemos que para esta autora el trabajo es work cuando es visto desde la sociedad en su conjunto, mientras que el trabajo como labour se definea partir del trabajador, del significado que el trabajo toma en su vida cotidiana (Heller, 1977: 119-125) ${ }^{8}$. En esta línea, se puede avanzar diciendo que work es el aspecto del trabajo más próximo a la escala macro de la

6 En el campo de la vida cotidiana mis principales referentes teóricos han sidb Michel Maffesoli, Michel de Certeau, Claude Javeau. Christian Lalive d'Epinay, Erving Goffman y Berger-Luckmann. De la geografía de las representaciones he tomado reflexionesde Antoine Bailly, Bernard Debarbieux, Armand Frémont. entre otros. En ambos casos lis bases filosóficas son de corte fenomenológico (paricularmente Alfred Schurz), por lo que el punto de partida es el referente egocéntrico de un individuo situado.

'Se trata de la zona comprendida en el municipio mexiquense recientemente creado: valle de Chalco-Solidaridad.

'También Hannah Arendt habla de la diferencia entre 'labor" y 'trabajo"; ella señala que el primero se refiere a las aaividades que no se definen por producir un objeto, sino por ser necesarias para la vida del hombre. En tanto que el segundo sería la actividad que origina productos duraderos. Para los efectos de este trabajo, la distinción de Heller puede resultar más cercana. Sin embargo, no se está siguiendo la perspectiva desarrollada por Heller sobre la vida cotidiana (Arendt, 1993:97-198). 
mundialización-globalización, y laboures su dimensión más próxima a la escala micro de la vida cotidiana. En otros términos, hablamos de trabajo como work cuando el enfoque parte de lo estructural; mientras que lo hacemos en términos de labour cuando partimos de los individuos.

La capacidad de la categoría trabajo de actuar como un puente entre la escala de los macroprocesos y la escala de las prácticas cotidianas, a mi modo de ver, se asocia fuertemente a la "espacialidad" del trabajo. Frecuentemente el trabajo ha sido visto como un puente entre niveles analíticos, aunque casi siempre ello se ha realizado a partir de otra dimensión de la categoría trabajo: las formas de inserción laboral. Sin pretender negar la capacidad interpretativa de las formas de inserción laboral, nos interesa regresar al trabajo visto desde los individuos, dándole prioridad a esta otra dimensión del trabajo, la espacialidad.

La posibilidad de considerar al trabajo desde la escala de lo microsocial, aunque vinculado a la escala macro; a los procesos de mundialización y reestructuración económica, se funda en el reconocimiento de que estos macroprocesos están transformando los procesos de trabajo, de producción y los factores de localización industrial.Estas transformacionessociales usualmente son analizadas como cambios en la organización de los espacios de la producción y cambios en la esfera de la producción en su conjunto; sin embargo, también pueden ser consideradas en cuanto a sus repercusiones en la vida cotidiana de las personas que realizan esos procesos de trabajo reestructurados.

Desde esta visión, la espacialidad del trabajo se torna en una de las principales dimensiones interpretativas, al igual que su temporalidad. Por ello, para comprender la vida cotidiana y el espacio vivido, creo que es más relevante considerar la espacialidad del trabajo (el lugar en donde se trabaja y los movimientosespaciales originados en el trabajo) y su temporalidad, antes que las formas de inserción en los mercados de trabajo (por su cuenta, o en forma asalariada) o el tipo de ocupación (actividad que se realiza) ${ }^{9}$. Aunque evidentemente hay una relación estrecha entre la espaciotemporalidad del trabajo y las formas de inserción laboral y el tipo de ocupación.

9 Posiblemente la espacialidad y la temporalidaddel trabajo no sean dimensiones analíticas más relevantes que la inserción y la ocupación, sino tan relevantes como ellas, aunque menos estudiadas.
Al considerar el trabajo como una categoría espacializada, la perspectiva metodológica en este artículo ha sido la de diferenciar dos subdimensiones espaciales. Una de ellas es el lugar de trabajo; la segunda viene dada por los movimientos en el espacio generados por aquél, o bien la ausencia de tales movimientos. En cuanto a la primera - el lugar de trabajo- la evidencia empírica muestra que los procesos de reestructuración económica (los procesos macro) están influyendo en la espacialidad del trabajo, de manera más concreta en la localización de los lugares de trabajo.

En las grandes áreas metropolitanas como la periferia de la ciudad de México, es posible encontrar diversas formas de trabajo domiciliario que en muchos casos recuerdan la organización de los talleres artesanales de la Edad Media (Pirenne, 1939:183). Esta localización del trabajo dentro del espacio de la vivienda, a veces tiene relación directa con la reestructuración económica (como la subcontratación domiciliaria), otras se trata de relaciones más indirectas, en las que si la reestructuración interviene es más por exclusión que por inclusión, como ocurre con la proliferación de los pequeños comercios domiciliarios ${ }^{10}$. Estos Últimos casos son los referentes empíricos de esta investigación ${ }^{11}$.

Así, parecería que el retorno del trabajo al lugar de residencia de las personas es un fenómeno frecuente. Sin embargo, no es el objetivo-be-este artículo analizar las mediaciones entre los niveles y las escalas, sino buscar estrategias metodológicas que permitan analizar las formas de articulación de la espacialidad del trabajo y la vida cotidiana ${ }^{12}$. En otras palabras, se busca la articulación entre lo histórico y lo cotidiano, conocer en qué forma

${ }^{10}$ En otros casos el lugar de trabajo se define en la vía pública. Este es otro tipo de espacialidad del trabajo que amerita ser analizada, aunque zquí no se considera porque en el caso que se analiza (el valle de Chalco) tiene muy escasa presencia.

${ }^{11}$ En la investigación empírica no sólo se analizan los casos en los que se da la unión del lugar de trabajo y el lugar de residencia, sino también aquellos que se caracterizan por la separación de ésos dos lugares. Es importante señalar que żl interés por conocer los casos en los que opera la unión del trabajo y la residencia no se funch en evaluaciones cuantitativas que indiquen a una 'supuesta mayoria"; no preocupan aquí las proporciones de un tipo de caso y otro; se cree que la sola presencia de los fenómenos amerita su conocimiento. Además de ello, se entiende que es relevante tener en cuenta que la organización de la cotidianidad a ello, se entiende que es relevante tener en cuenta que la organización de la cotidianidad a partir de la separación del lugar de trabajo y $e l$ lugar de residencia es mas conocida que la modo de vida obrero y las periferias dormitorio.

${ }^{12}$ Analíticamentese considerancuatro esferas de la vida cotidiana: la laboral, la doméstica, la del ocio-tiempo libre y el vecindario. 
el proceso histórico del retorno del trabajo al lugar de residencia influye en la conformación de las prácticas cotidianas.

En cuanto a la segunda dimensión de la espacialidad de trabajo (los movimientos cotidianos en el espacio de vida)) la citada localización del mismo en el hogar produce una disminución de los movimientos espaciales de las personas, ya que una grao parte de los desplazamientos que los individuos realizan cotidianamente se deben al trabajo, concretamente al trayecto obligado por la separación entre los lugares de trabajo y los de residencia.

Este fenómeno -la escasa movilidad cotidiana en el espacio- tiene influencia en las representaciones del espacio que las personas manejan (Moscovici, 1988)" y repercute en la construcción del imaginario espacial. Por su parte, las representaciones del espacio que tienen las personas influyen en la construcción del espacio social (Chalas, 1984:489-506). Recordemos que las representaciones son sistemas de nociones asociados a redes de imágenes que actúan como filtros orientadores de las acciones". Este tipo de cuestiones abren interrogantes acerca de la relación entre el imaginario espacial de las personas (cómo piensan y viven interiormente el espacio) y la unión del lugar de trabajo y el de residencia.

La relación trabajo/residencia y los ámbitos de la vida cotidiana

La consideración de la categoría trabajo en términos espaciales condujo a redefinirlo en esta otra categoría más compleja: la "relación trabajo/residencia ${ }^{\mathrm{n}}$ (Touraine, 1962:203-224); (Chombart de Lauwe y Jenny, 1963:324-344); (Chombart de Lauwe, 1963:329$340)^{15}$. Así, la anterior es una categoría referida a los espacios de vida de las personas que trabajan. Estos espacios pueden ser vistos

${ }^{3}$ Se toma el concepto de representación social en la perspectiva de la psicología social planteada por Serge Moscovici y sus discípulos: Zavalloni, Jodelet y Farr.

${ }^{14}$ Recordemos que las nociones son conocimientos elementales adquiridos en la vida cotidiana por medio del "sentido común".

${ }^{15}$ Los antecedentes teóricos respecto de esta categoría se hallan en la obra de la primera época de Alain Touraine y también la de Paul-Henry Chombart de Lauwe, que ubica su visión en términos disciplinarios'entre la geografía y la sociología". En un articulo publicado recientemente en Sociología del Trabajo se plantea que "là relación entre la casa y el trabajo vuelve a estar de moda" (Estivill, 1993:147-173). como los lugares frecuentados por un grupo social a un individuo que se siente parte de ese espacio, mientras que el "espacio vivido" da cuenta de un lugar frecuehtado y del que se forma parte, en el que se distinguen distancias sociales pero también en donde la persona puede distinguir distancias afectivas (Bailly, 1992:371-384); (Bailly y Debarbieux, 1991:153-161).

El lugar de trabajo y ef de residencia son dos,espacios de vida que al mismo tiempo haceh referencia a dos ámbitos de relaciones sociales del individuo; el laboral (lugar de trabajo) y el familiar (lugar de residencia). Ambas, como espacios de vida, unas veces se superponen, conformando un único espacio vivencial; en otros casos son dos espacios de vida diferentes y separadas por espacios de tránsito. En otras ocasiones el lugar de trabajo se materializa como una multiplicidad de espacios de vida; en general esto último ocurre cuando el trabajo adquiere el carácter de "ambulante", es decir, cuando no se fija espacialmente. Al respecto, destaquemos que la noción de trabaja ambulante - tan utilizada en las perspectivas que analizan el empleo y la inserción laboral-toma contenido a partir de la espacialidad que le es propia.

En esta propuestala "relación trabajo/residencia" comprende tres situaciones principales (metodológicamente debería hablarse de tres categorías): a) lugar de trabajo y residencia unidos; b) lugar de trabajo y de residencia separados en el conjunto territorial metropolitano; $y, c$ ) lugar de trabajo y de residencia separadas y próximos. La primera de estas situaciones refiere a un espacio vivido, en tanto que las dos últimas permiten postular la existencia de espacios de vida y espacios vividos.

Esta construcción de la "relación trabajo/residencia" viene a constituir en esta propuesta una de las dos entradas al estudia de lo que aquí se esta denominando trama de la vida cotidiana. La ségunda vía de entrada se orienta hacia los diferentes ámbitos ea los que se puede subdividir analíticamente a dicha trama. En relación con lo anterior, y desde una perspectiva espacio-temporal, es importante distinguir ámbitos, que en este caso han sido los siguientes: a) laboral; b) del tiempo libre; c) doméstico; $\mathrm{y}$, d) vecina ${ }^{16}$. Se purede observar que estos cuatro ámbitos se distinguen entre sí por las actividades que les son propias, por la naturaleza de

${ }^{16}$ Se podrian distinguir otros ámbitos de análisis, como por ejemplo uno político, otro religioso. No obstante, la delimitación de estos cuatro ámbitos deriva del referente empírico en relación con el cual se construyó esta estrategia. 
las interacciones sociales que en ellos se desarrollan y también por su espacialidad.

En relación con. el tiempo libre, éste se refiere a aquellas prácticas espacialmente externas a la vivienda y también a las otras que se hacen adentro de la vivienda (como ver la televisión). La misma estrategia se ha tomado en relación con el ámbito doméstico, en donde la mayor parte de las prácticas cotidianas, aunque no todas, se desarrollan dentro de la vivienda.

Respecto del ámbito vecinal, señalemos que en términos territoriales corresponde al concepto de barrio (Mayol, 1994:15-24). El vecindario se refiere al ámbito de un tipo de interacciones sociales, en tanto que el barrio da cuenta de esas interaccione sociales y también de la territorialidad a ellas asociada. Se puede decir que éste es la parte del espacio público en el cual se insinúa un espacio privado por medio de prácticas cotidianas asociadas con la fijación del hábitat, con el acostumbramiento recíproco al vecindario, y con los procesos de identificación que resultan de la proximidad física y la coexistencia en un mismo territorio urbano.

La consideración de la espacialidad de los cuatro ámbitos tiene la ventaja de permitir estudiar la vida cotidiana hacia adentro y hacia afuera del hogar. Esto significa estudiarla en espacios de vida en los cuales se incorporan cercanías afectivas (lo interno al hogar, como espacios vividos) y otros en los que predominan las distancias afectivas (lo externo, como espacios de vida que pueden llegar a constituir espacios vividos).

Esta estrategia metodológica que se ha seguido para el estudio de la trama de la vida cotidiana ha partido de la búsqueda de toda la pluralidad de formas que pueden asociarse con la "relación trabajo/residencia", pata luego explorar la interacción entre esa diversidad contenida en la relación trabajo/residencia y cada uno de los ámbitos o esferas de la vida cotidiana. Todo ello con miras a la construcción de tipos de formas de constitución de la vida cotidiana".

Desde esta perspectiva metodológica, la articulación entre la relación trabajo/residencia y los cuatro ámbitos seleccionados es la forma de acercarnos a la concepción de la vida cotidiana como una

${ }^{17}$ L 2 dimensión técnica de este procedimiento de construcción de tipos no se está considerando, ya que ello superaría los objetivos de este breve artículo. Aunque puede señalarse que se realizó una primera tapa de ańlisis cuantitativo multivariado panidentifice conjuntos de prácticas cotidianas, luego procedió al ańlisis cualitativocomo 'ú́lis de contenido de tipo interpretativo" y por último, los tipos construidos. trama. La idea de trama expresa fa integración de un fondo y unos vínculos sociales (Javeau, 1991:292; Lindón, 1996:156-176) ${ }^{18}$. En este caso, se considera que el fondo de la trama es el tiempo cotidiano y también los espacios en los que se dispersa la cotidianidad; en tanto que los vínculos corresponden a ciertas relaciones sociales muy estructurantes de la vida cotidiana, como los roles conyugales. La opción por este tipo de vínculo social primario se debe a la importancia que tienen los hogares de tipo nuclear -con núcleo comp̄leto- en el contexto de la zona del estudio empírico.

Es necesario observar que no se incluyen los roles conyugales como roles individuales vistosen un contexto social, sino como roles relacionales; es decir, el concepto de roles conyugales nos permite preguntarnos: cómo se interrelacionan cotidianamente ambos cớnyuges con referencia a las prácticas cotidianas ${ }^{19}$. Desde esta óptica, los roles conyugales sólo se pueden estudiar con respecto al desarrollo de las distintas prácticas cotidianas que realizan las personas-cónyuges ${ }^{20}$. planteada:

A continuación esquematizamos la propuesta metodológica

\begin{tabular}{|c|c|}
\hline Relación trabajo/residencia & Vinculos sociales (roles conyugales) \\
\hline \multicolumn{2}{|c|}{ - $\rightarrow$ Trama de la vida cotidiana $\rightarrow$} \\
\hline $\begin{array}{l}\text { Ámbitos de la vida cotidiana } \\
\text { (doméstico, laboral, vecinal, } \\
\text { tiempo libre) }\end{array}$ & $\begin{array}{l}\text { Fondo espacio-temporal } \\
\text { (espacios de vida/ciclo cotidiano) }\end{array}$ \\
\hline
\end{tabular}

${ }^{18}$ En principio el término "trama de la vida cotidiana" se toma de Claude Javeau, no obstante se ha intentado darle nuevo contenido sociológico, o al menos explicitarlo.

" Esta perspectiva nos permitio distinguir roles conjuntos, complementarios y paradas o segregados. La primen categoría refiere a la participación conjunta de los dos cónyuges en ciertas prácticas. La segunda indica la situación en la que cada uno de lar cónyuges participa en dichas prácticas, pero en forma independienteel uno del otro. La tercera categoría muestra las situaciones en las cuales uno de lar cónyuges no participa en ciertas practicas cotidianas. La perspectiva de los roles indivituales en contertos sociales hubiesen llevado a distinguir, por ejemplo. rol de esposo proveedor, de madreesposa, etc. Posiblemente, ese es un camino fructífero para estudiar otras temáticas. Para el estudio de la vida cotidiana y sus espacios de dispersión se encontraron mas posibilidades ex $\mathrm{h}$ anterior línea

"Me refiero a "prácticas" en la perspectiva que Alfred Schutz denominaba "ejecuciones", diferenciándolas así de las acciones sociales en términos generales, ya que las ejecuciones o

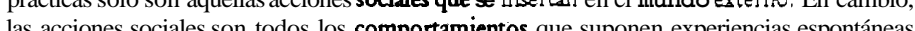
la 
En síntesis, se busca construir una respuesta metodológica a la siguiente pregunta de investigación: ¿cómo estudiar la vida cotidiana desde una perspectiva espacio-temporal?

Este enfoque metodológicoha permitidoencontrar dos tipos polares de formas de constitución de la vida cotidiana ${ }^{21}$. Uno de ellos se caracteriza por la dispersión de la cotidianeidad en múltiples espacios de vida, al menos en el caso de uno de los cónyuges. Estos espacios de vida encuentran correspondencia con los "pequeños mundos de vida", sobre los que ha reflexionado Benita Luckmann (1978:275-290). En el tipo opuesto, se encuentran patrones de fuerte concentración espacial de la cotidianidad. Este segundo tipo coincide con aquellos hogares en los que se ha producido la unión del lugar de trabajo y el de residencia para ambos cónyuges. La dispersión, en cambio, se ajusta a los hogares en los que uno de los cónyuges divide su existencia entre dos ámbitos separados y diferenciados: el lugar de trabajo y el de residencia, en tanto que el otro cónyuge la fragmenta en múltiples ámbitos de la socialidad, cada uno con una espacialidad propia: el vecindario, el trabajo, el hogar y ciertos ámbitos del tiempo libre.

Los patrones de concentración espacial de la cotidianeidad (el segundo tipo) van asociados a la vivencia interior del tiempo cotidiano como un continuo indiferenciado que involucra al grupo familiar en su conjunto. En ese tiempo cotidiano continuo no se desarrollan actividades que puedan significar separaciones entre ámbitos de la socialidad o en fragmentos de tiempo (Durán, 1988:460). Desde el ángulo de los roles conyugales, esta situación se asocia a la conjunción conyugal en casi todos los ámbitos de la cotidianidad; se puede decir que los cónyuges comparten la realización de la mayor parte de las actividades cotidianas, tanto las laborales como las domésticas.

En este tipo se ha encontrado que la concentración de la espacialidad cotidiana en la vivienda es de tal intensidad que el barrio, entendido como el entorno socioespacial inmediato del hogar, no llega a vivirse como un espacio apropiado por las personas, reduciéndose éste a la vivienda y su entorno más próximo. El espacio de vida dentro de la vivienda adquiere una fuerte centralidad, en la que las relaciones familiares articulan lo laboral y lo emocional, mientras que se acentúa el distanciamiento respecto a los ámbitos sociales externos, tanto al vecindario como a la parentela

${ }^{21}$ En realidad, en la investigación empirica se han construido tres tipos. Aunque en este trabajo sólo se hace referencia a dos de ellos. que no es corresidente. Estos últimos no llegan a constituir.espacios vividos, con la particularidad de que el lugar de trabajo (en el que también se reside) toma el carácter de espacio vivido y no sólo espacio de vida.

Esta Última situación viene a constituir una forma de invención de la cotidianeidad a través de la espacialidad; al igual que la conjunción conyugal es una forma de invención desde la socialidad. No podemos dejar de subrayar que el hallazgo de este tipo de forma de invención de la cotidianeidad ocurra en hogares en los cuales el trabajo ha sido, al menos parcialmente, recreado en sus formas y en su espacialidad por los propios individuos que lo realizan y fuera del vínculo con lo estructural que significa el asalariamiento.

El tipo opuesto, el fundado en la dispersión de la vida cotidiana en múltiples espacios de vida, se asocia con la vivencia interior del tiempo cotidiano de manera fragmentada. En relación con los roles conyugales se encuentra que el trabajo se desarrolla bajo pautas de complementariedad; es decir, ambos cónyuges desarrollan actividades laborales, pero en forma independiente uno respecto del otro. En tanto que en el ámbito doméstico se detectan patrones de conjunción conyugal: las actividades domésticas son compartidas por ambos cónyuges.

En relación con el ámbito externo al hogar, el vecindario, se destaca el sentido de pertenencia de ambos cónyuges respecto al barrio. Se puede decir que una fuerte apropiación del territorio barrial marca la forma de interacción con el vecindario, sin interposición de distancias sociales. Se trata de interacciones en la cercanía social, lo cual no excluye el conflicto, que constituyen al barrio en un espacio vivido.

Por Último, esta estrategia analítica introduce la consideración de los significados que cobran esas prácticas cotidianas espacializadás y temporalizadas. Los significados de tales prácticas interesan a fin de comprender si la vida cotidiana se presenta como una invención o creación, o si se vive como simple alienación en la repetición. En otras palabras, permite indagar cuándo las prácticas cotidianas son significadas como rutinas y cuándo toman el carácter de rupturas de la cotidianidad, o por lo menos nos indica cuándo constituyen formas de invención no repetitivas (Lalive d'Epinay, 1983:13-38).

Al dejar abierta la posibilidad de que cualquier práctica cotidiana sea vividacomo un acontecimiento, se asume la posibilidad de la invención de lo cotidiano. Con ello se recupera empíricamente 
la tesis central de Michel de Certeau en torno a la concepción de la vida cotidiana como invención (De Certeau, 1990). En otros términos, no se considera aquí que la vida cotidiana deba ser asimilada necesariamente a lo alienante, wmo sostuvo el pensamiento marxista dedicado al tema (Lefebvre; 1972; Heller, 1977).

El retorno histórico del trabajo al lugar de residencia, al menos en los sectores populares urbanos, resemantiza el sentido que toma "el acontecimiento ${ }^{\mathrm{n}}$ en la vida cotidiana, pudiendo constituirse en un fenómeno social que indirectsmente permite que los individuos encuentren formas de invención o de cuasi-invención de su cotidianeidad, difícilmente recreables cuando el trabajo está anclado en un espacio de vida ad-boc.

Desde este enfoque,.la vivencia del espacio puede constituir una forma de buscar la invención o bien la repetición. El tipo de constitución de la vida wtidiana fundado en la dispersión ¿e la existencia en múltiples espacios de vida halla lo renovado en esa dispersión espacial; en cada espacio se desarrollan distintas pautas de interacción social, distintas normatividades; diferentes encuentros cara a cara.

Por su parte, el tipo opuesto basado en la concentración de la existencia en un Único espacio de vida, tiene más dificultades para recrear la invención en lo cotidiano, y sólo la puede recrear en espacios y tiempos de tipo "intersticial". Los espacios-tiempos intersticiales representan fugas espontáneas de la dinámica que perdura (la dominada por el trabajoen un contexto familiar); que no están preestablecidos ni espacial ni temporalmente, w mo puede estar predeterminado un día libre en el calendario de un obrero asalariado. Los espacios-tiempos intersticiales representan pequeñas fugas del lugar de trabajo y residencia regido por una lógica laboralfamiliar particular, ya que se desarrolla en interacciones familiares teñidas por la dimensión emotiva. Esas salidas a espacios intersticiales en el conjunto de la trama de la vida cotidiana no tienen ni horarios fijos, ni una espacialidad preestablecida. En ese sentido tienen la capacidad para introducir una forma de invención o de cuasi-invención en la vida cotidiana, aun cuando sea instantánea.

\section{Algunas reflexiones finales}

Esta propuesta metodológica presenta una forma de estudiar la vida cotidiana de los sectores populares de la periferia metropolitana desde la perspectiva de los espacios vividos, desde las vivencias espaciales de las personas, partiendo de la centralidad que adquiere en ello el lugar de trabajo como estructurante de la vida cotidiana. Tal estrategia, pensada desde un enfoque próximo a la subjetividad de las personas, también da cuenta de un enfoque espacial particular para estudiar la vida social desde las vivencias interiores y exteriores de los individuos en interacción (Schutz, 1974) ${ }^{2}$, antes que desde la otra perspectiva más conocida vinculada a lo macrosocial, que hemos definido como el enfoque de la organización del espacio.

La naturaleza del camino metodológico construido permite conocer la trama de la vida cotidiana desde su espacialidad, diferenciando todo el espectro' de situaciones que van desde la dispersión espacial hasta la concentración absoluta de la cotidianeidad en un único espacio de vida. En cuanto al tiempo, hace Dosible reconocer cotidianeidades desarrolladas como una continuidad en las que no se producen separaciones y también aquellas que se fraginentan temporalmente. Por último se puede destacer que, al incorporar la forma en que son significadas las vivencias espaciales, estaestrategia metodológica permite comprender las diversas formas en que la vida cotidiana puede incluir la invención, aun cuando sean formas imaginarias, temporalmente intersticiales, o instantáneas.

En cuanto a los dos tipos que se han construido a partir del caso empírico estudiado (los hogares del valle de Chałco), se considera relevante el hallazgo de formas de invención y cuasiinvención de la cotidianeidad asociadas a la dispersión y la concentración de la espacialidad del trabajo.

\section{Bibliografía}

Arendt, H. (1993), La condición humana, Barcelona, Paidós, Col. Paidós Estado y Sociedad. 
Bailly, A. (1992), "Les répresentations en géographie", en A. Bailly, R. Ferras y D. Pumain (directores), Encyclopédie de Géographie, París, Económica, pp. 371-384.

y B. Debarbieux (1991), “Géographie et répresentations spatiales”, en A. Bailly (coord), Les concepts de la géographie humaine, París, Masson, pp. 153-161.

Berger, P. y T. Luckmann (1968), La construcción social de la realidad, Buenos Aires, Amorrortu.

Chalas, Y. (1984), "L'imaginaire habitant", Revue de l'Institut de Sociologie, núms. 3/4, Université Libre de Bruxelles, pp. 489. 506.

Chombart de Lauwe, P.M. (1963), "La vida familiar y los presupuestos", en G. Friedmanin y P. Naville, Tratada de Sociologia del Trabajo, vol. II, México, FCE, pp. 329-340.

y J. Jenny (1963), "Lugar de trabajo y residencia", en G. Friedmann y P. Naville, Tratado de Sociología del Trabajo, vol. I, México, FCE, pp. 324-344.

Dahrendorf, R. (1979), Life chances. Dimensions of liberty in society, en Life Chances. Approaches to Social and Political Theory, Chicago, The University of Chicago Press.

De Certeau, M. (1990), L'invention du quotidien. 1. Arts de faire Párís, Gallimard, Col. Folio-Essais, núm. 146.

Durán, M.Á. (1988), "Los límites del hogar", en M.Á. Durán (directora),Depuertasadentro, Madrid, Instituto de la Mujer, Serie Estudios, núm. 12.

Durand, G. (1981), Las estructuras antropológicas de lo imaginario (introducción a la arquetipología general), Madrid, Taurus, Col. Ensayistas.

Estivill, J. (1993), "Casa y trabajo: entre la reclusión y la itinerancia", Sociologiá del Trabajo, invierno de 1992/1993, Madrid, Siglo XXI España, pp. 147-173.

Frémont, A. (1976), La région, espace vécu, París, PUF.

García Ballesteros, A. (1986), “Espacio masculino, espacio femenino? Notas para una aproximación geográfica al estudio del uso del espacio en la vida cotidiana”, en A. García Ballesteros (coord.), El uso del espacio $\mathrm{m}$ la cotidiana, Madrid, Universidad Autónoma de Madrid, Seminario de Estudios de la Mujer, pp. 13-27.

Giddens, A. (1995), La constituciónde la sociedad. Bases para la teoría de la estructuración, Buenos Aires, Amorrortu.

Goffman, Erving (1981), La presentación de la persona $\mathrm{m}$ la vida coditiana, Amorrortu Editores, Buenos Aires.

Heller, A. (1977), Sociología de la vida cotidiana, Barcelona, Ediciones Península, Col. Historia/Ciencia/Sociedad.

Javeau, C. (1991), La société au jour le jour; écrits sur la vie quotidienne, Bruselas, De Boeck Université, Ouverture Sociologiques.

Lalive d'Epinay, C. (1983), "La vie quotidienne. Essai de construction d'un concept sociologique et antropologique", Cabiers Internationaux de Sociologie, vol. LXXIV, París, PUF, pp. 13-38.

(1990), "Récit de vie, ethos et comportement: pour une exégèse sociologique", en Remy, J. y D. Ruquoy (dirs), Methodes d'analyse de contenu et sociologie, Bruselas, Faculté Universitaire Saint-Louis.

(1994), "Signitications et valeurs du travail, de la société industrielle à nos jours", en, De Coster, M. y F. Pinchault (comps.), Traité de sociologie $d u$ travail, Col. Ouvertures Sociologiques, Bruselas, De Boeck Université.

Lefebvre, H. (1972), La vida cotidiana en el mundo moderno, Madrid, Alianza Editorial.

Lindón, A. (1996), El trabajo y la vida cotidiana. Los modos de vida urbanos en el valle de Chalco, tesis de doctorado en ciencias 
sociales con especialidad en sociología, CES, El Colegio de México.

Luckmann, B. (1978), "The small life-worlds of modern man", en T. Luckmann, Phenomenology and Sociology, Harmondsworth, Penguin Books/Peregrine Books, pp. 275-290.

Maffesoli, M. (1991), Le temps des tribus, le déclin de l'individualisme dans les sociétés de masses, París, Editions Méridiens Klincksieck, Col. Le livre de poche.

(1992), La transfiguration $d u$ politique. La tribalisation $d u$ monde, París, Grasset.

(1993), La contemplation $d u$ monde. Figures $d u$ style communautaire, París, Grasset.

Mayol, P. (1994), "Habiter", en M. de Certeau, L. Giard y P. Mayol, L'invention $d u$ quotidien. 2 Habiter, Cuisiner, París, Gallimard, Col. Folio-Essais, pp. 15-24.

Michel, A. (1974), Sociología de la familia y del matrimonio, Barcelona, Ediciones Península, Col. Historia/Ciencia/Sociedad.

Moscovici, S. (1988), Psicología social, II. Pensamiento y vida social. Psicologíá social y problemas sociales, Madrid, Paidós, Col. Cognición y Desarrollo Humano.

Ortega y Gasset, J. (1983), "Algunos temas del weltverkebr", Obras Completas, tomo IX, Madrid, Alianza Editorial-Revista de Occidente, pp. 339-343.

Pirenne, H. (1939), Historia económica y social de la Edad Media, México, FCE.

Przeworski, A. (1982), "La teoría sociológica y el estudio de la población: reflexiones sobre los trabajos de la comisión de población-y desarrollo de CLACSO", en Reflexiones teóricometodológicassobre la investigaciónen población, México, El Colegio de México, pp. 58-99.
Sansot, P. (1971), Poétique de la ville, París, Klincksieck.

(1991), Les gens $d u$ peu, París, PUF, Col. Sociologie d'aujour d'hui.

Schutz, A. (1974), Estudios sobre la teoría social, Buenos Aires, Amorrortu.

(1962), El problema de la realidad social, Buenos Aires, Amorrortu.

Touraine, A. (1962), "La vie ouvrière", en L.H. Parias (director), Histoire Général du Travail, La civilisation industrièlle (de 1914 à nos jours), París, Nouvelle Libraire de France, pp. 203-224.

(1994), Crítica de la modernidad, Buenos Aires, FCE.

Wright Mills, C. (1961), La imaginaciónsociológica, México, FCE 


\section{Reseña}

Gustavo Garza, Cincuenta años de investigación urbana y regional en México, El Colegio de México, México, 325 pp.

En este libro el autor describe el desarrollo de la investigación urbana y regional en México en el periodo 1940-1991. Para ello la estructura del texto se compone de un prólogo, seis capítulos, un apéndice bibliográfico y un anexo de las 1,831 referencias bibliográficas recopiladas según disciplinas.

El título del libro podría dar cabida a varias interpretaciones sobre el contenido, por lo que en el prólogo se menciona claramente lo que el texto es y lo que no es. Para comenzar se menciona que las variables de análisis de la ciencia regional son la población y las actividades económicas, las cuales pueden ser interpretadas a nivel urbano o regional; y los tipos de investigación son descriptiva o analítica. Esta ciencia regional ha sido abordada desde varias disciplinas, como sociología, antropología, urbanismo, demografía, geografía, historia, economía, planeación y ecología.

La utilidad del texto consiste en ser una monografía de consulta para avanzar en el conocimiento sobre el estado de avance de la investigación urbana y regional en México. Su metodología se basa en una evaluación cuantitativa y temática de 1,831 publicaciones, las cuales canstituyen, según palabras del autor, una muestra altamente representativa por haber considerado principalmente trabajos de instituciones y revistas especializadas relevantes.

La limitación más importante radica en el hecho de ser una descripción y no un análisis de los aspectos teóricos y metodológicos de las referencias bibliográficas recopiladas. Sin embargo, según el 
autor, resolver esa limitación significaría un trabajo de aproximadamente diez años. A esta limitación se sumaría otra relacionada con la significancia cualitativa, pero tal vez no estadística, de la muestra utilizada. Es decir, merecida o inmerecidamente existirán quejas por la no inclusión de una serie de trabajos.

Los capítulos 1 al 5 van describiendo cronológicamente la evolución de la investigación urbana y regional en el país, desde sus albores hasta el auge ocurrido en la década de los ochenta. De las 1,831 referencias, $66 \%$ son trabajos relacionados con lo urbano y $34 \%$ con lo regional. Las disciplinas con mayores aportaciones son sociología y urbanismo, que representan $45 \%$ de los estudios, seguidos por demografía con $13 \%$ y economía con 12 por ciento. El ámbito urbano más estudiado ha sido la ciudad de México, con $60 \%$ de las referencias incluidas. En cuanto al tipo de publicaciones, los artículos representan 34\%, 32\% de libros, y capítulos de libros con 18 por ciento.

La investigación realizada en los periodos analizados guarda estrecha relación con las teorías internacionales en boga de la ciencia regional. En los cuarenta y cincuenta predominaron aquellos estudios bajo la perspectiva de la ecología humana desarrollada en la Escuela de Chicago; en los sesenta se privilegió la corriente cepalina de dependencia, modernidad y marginalidad, así como el estudio de las migraciones; entre los setenta y mediados de los ochenta se abocaron a la interpretación en el contexto nacional de los postulados de la sociología urbana francesa; y finalmente en las posrrimerías de los ochenta aparecieron trabajos vinculados con políticas estatales de ajuste neoliberal, resurgimientodel positivismo y empirismo, y la pérdida relativa de una visión de conjunto para concentrarse en aspectos específicos o parciales.

Un aspecto que llama la atención, y tal vez por razones obvias, es que en el capítulo 4, donde se habla de la institucionalización de la investigación espacial, 1971-1980, no se resalta el rol del libro El desarrollo urbano de México. Diagnóstico e implicaciones futuras, realizado por Luis Unikel en colaboración con Crescencio Ruiz y el propio Gustavo Garza. Es indudable que este texto, aparecido en 1976, constituye la visión macroestadística y metodológica más importante sobre el estudio de la ciencia regional en México, y que de manera directa influyó en el auge de la investigación urbana y regional en los años ochenta. Desde mi punto de vista, el libro mencionado se convirtió en un parteaguas sobre la forma de entender e investigar al desarrollo urbano en el país, y no tengo duda que es el libro del que se ha hecho el mayor número de citas y referencias bibliográficas dentro de nuestra disciplina,

Del capítulo 6, dedicado a las conclusiones, se pueden extraer tres puntos fundamentales:

a) Articulación entre docencia e investigación, la cual toma un gran dinamismo en la década de los ochenta, cuando aparecieron $\mathbf{7 0 \%}$ de los programas docentes existentes en el país. Esta articulación presenta retos y obstáculos, por lo que no se debe hablar ya de su consolidación.

b) Urgencia de profundizar en el nivel teórico y metodológico de las investigaciones, lo que implica imaginar y desarrollar enfoques con mayor rigor científico. En este punto, el autor menciona una dependencia teórica y metodológica en la investigación del país, aunque yo no estoy totalmente de acuerdo con dicha aseveración, ya que es incuestionable el avance teórico e indagatorio sobre algunas especificidades del desarrollo urbano y regional ocurrido en el país, sobre todo en materias relacionadas con proceso de urbanización y ocupación del suelo, factores de concentración económicodemográfica, movimientos migratorios y sistemas de ciudades.
-

Agenda de investigación para los próximos años, es decir aspectos que no han sido tratados con suficiencia o que emergen como nuevos objetos de estudio. En esta agenda se proponen por lo menos nueve temas centrales: política poblacional, revolución tecnológica y factores locacionales, sector terciario en las economías urbanas, servicios públicos desde la óptica de la teoría económica espacial, privatización de servicios públicos, problemática ambiental, prospectiva de la urbanización, gestión y naturaleza de los gobiernos locales y participación ciudadana en el proceso de urbanización y toma de decisiones. 
En síntesis, el libro recibe nota de aprobación y recomendación por hạber alcanzado su objetivo respecto a la presentación de una descripción del desarrollo de la investigación urbana y regional en México en el período 1940-1991.

Jaime Sobrino

El Colegio Mexiquense

Ex-Hacienda Santa Cruz de los Patos

Apartado Postal 48-D

Toluca 50120, Estado de México

Tel. (72) 180056

Fax (72) 180358 